Article

\title{
Innovation within the Context of Local Economic Development and Planning: Perspectives of City Practitioners
}

\author{
Selina Phan ${ }^{1, *}$, Evan Cleave ${ }^{2}$ and Godwin Arku ${ }^{1}$ \\ ${ }^{1}$ Department of Geography, University of Western Ontario, London, N6A 5C2, Canada; E-Mails: sphan6@uwo.ca (S.P.), \\ garku@uwo.ca (G.A.) \\ 2 Department of Geography \& Environmental Studies, Ryerson University, Toronto, M5B 2K3, Canada; \\ E-Mail: evan.cleave@ryerson.ca \\ * Corresponding author
}

Submitted: 1 April 2020 | Accepted: 7 July 2020 | Published: 29 September 2020

\begin{abstract}
Although innovation is a major theme in current local economic development and planning, there is considerable uncertainty of what the concept specifically means, how it is measured, and how outcomes are identified. To date, no study has investigated this glaring gap in scholarship. To address this gap, we interviewed economic development practitioners across cities in Ontario to identify and clarify how they define, apply, and measure innovation within their cities' economic development strategies. Practitioners indicate that innovation plays a key role in their cities' economic development strategy, demonstrating the importance of the concept within local governments. Additionally, it is clear that local governments are key facilitators of innovation. While many cities claim to have some form of innovation in their economic development strategies, a wide range of framings and approaches to innovation exist. Cities may not be taking the most efficient approach to fostering local innovation, which is critical with the rise of knowledge-based economic development.
\end{abstract}

\section{Keywords}

cities; economic development; innovation; Ontario; policy; practitioners

\section{Issue}

This article is part of the issue "Planning for Local Economic Development: Research into Policymaking and Practice" edited by Godwin Arku (University of Western Ontario, Canada) and Evan Cleave (Ryerson University, Canada).

(C) 2020 by the authors; licensee Cogitatio (Lisbon, Portugal). This article is licensed under a Creative Commons Attribution 4.0 International License (CC BY).

\section{Introduction}

This article explores innovation's place within local economic development planning and activity. In doing so, it also critically examines the role of local governments and economic development practitioners with the emergence and growth of innovation. The emergence of a globalizing, knowledge-based economy has accentuated the challenges facing policymakers, especially at the local level (Bramwell, Nelles, \& Wolfe, 2008). Concern with both emerging sources of global competition and the necessity of continuous innovation has focused their attention on the available strategies to respond to these challenges.
The emphasis on innovation by local governments is an outcome of nearly five decades of political-economic change and challenges. Since the 1970s, cities and their governments have faced critical challenges within their local economies, spurred on by broad political-economic changes including the replacement of Keynesian theories of economy and employment with neoliberal ones, the decentralisation of state political and decision-making power, the transition to post-Fordism, and the rise of globalization (Arku, 2015; Bradford \& Wolfe, 2013; Wolfe, 2009a; Wolfson \& Frisken, 2000). For cities in advanced economic regions-like the province of Ontario, Canada-the outcome of all these processes was newly empowered city governments, now responsible for all 
aspects of community development, managing local economies that were no longer efficient. The decadeslong decline of tradition manufacturing in Ontario and other advanced economies has been well documented (see Cleave, Vecchio, Spilsbury, \& Arku, 2019; Holmes, Rutherford, \& Carey, 2017; Sadler, Cleave, Arku, \& Gilliland, 2016; Wolfe \& Gertler, 2001); but for the purposes of this article, the economic development response of cities needs to be considered. Within local economic development, practitioners have used their newfound power and autonomy to emphasize new approaches to economic development that focus on highlyskilled labour, advanced production practices, creativity, and knowledge-production to meet these emerging responsibilities and support their local constituents (Bramwell et al., 2008; Taabazuing, Arku, \& Mkandawire, 2015). In short, local governments are now focusing on innovation as a key tool of local economic development, as "decision makers in large cities have fully embraced the idea that cities are key players in the innovation game" (Shearmur, 2007, p. 511).

But what does being in the innovation game mean for cities? While it is understood that the competitive success of cities is now "highly dependent on localized, or regionally-based, innovation" (Wolfe \& Gertler, 2001, p. 577), there are still several areas of uncertainty about what cities can and should be doing. Economic activity, however, is situated and must be understood as embedded within structures of economic and political rules and procedures (Martin, 2003; Vidal \& Peck, 2012). In this sense, the rise of innovation within local economies "cannot be fully understood without giving due attention to the various social institutions on which depends and through which it is shaped" (Martin, 2003, p. 77). Here, social institutions include local governments-and the practitioners and policymakers they employ-as key local actors who can shape the local context in which firms operate and innovation situates through planning, policy, and action. Indeed, Wolfe and Bramwell (2016, p. 460) argue that "a key question for policymakers at the local level is how to create the right conditions for generating the growth of more knowledge-intensive forms of economic activity." Answering this question is multifaceted, as innovation and how it manifests within cities is complex.

There is surprisingly limited knowledge on how those responsible for developing and integrating innovation into local economic development view it. And how they view it will have implications for what types of firms are targeted, the structure of the local economy, and how they interact with other institutions within their jurisdiction. Despite its emphasis as a policy approach, Lundvall, Johnson, Andersen, and Dalum (2002) argue that within both research and practice there is a lack of a consistent understanding about what innovation is. This creates challenges in how to apply effective and meaningful policies. This study aims to fill this gap by understanding how economic development practitioners contextu- alize and understand innovation through in-depth interviews with officials from cities in Ontario. In doing so, this study will investigate the following research questions: 1) What does innovation mean to cities and their practitioners in the context of economic development? 2) How do cities, as social institutions, operationalize innovation policy within their local context? In doing so, the strategies, challenges, and opportunities that cities face as being key institutions in developing and implementing innovation policy are explored.

To evaluate these research question, a series of semistructured qualitative interviews were conducted with economic development practitioners from cities across the province of Ontario, Canada. This presents a unique avenue for research, as previous innovation studies have focused on regional development (see Asheim \& Gertler, 2006; Bradford \& Wolfe, 2013) or other institutions that contribute to economic growth (see Bramwell \& Wolfe, 2008; Shearmur, 2011; Shearmur \& Doloreux, 2009; Wolfe, 2009b). To date there have not been any comprehensive studies on how economic development practitioners view, understand, and approach innovation policy development despite the fact that they (and the local institutions that they represent) are central actors in creating the local framework for economic growth through the formulation and implementation of regulation and planning policies. The perspectives and knowledge of these practitioners is important, as local governments in Ontario have been forced to take more rigorous and proactive approaches to economic planning ahead of their contemporaries in other advanced economies. Understanding perspectives and processes related to innovation that have occurred in Ontario from those vital in framing it can help inform policy analysis and progression in other regions.

\section{Study Context: Innovation and Local Economic Development Governance}

The linkages between innovation and economy have long been understood, as innovation has been at the core of economic development since at least the industrial revolution (Hall, 1999; Shearmur, 2009, 2012), and remains a key driver of local and regional economic growth (see Brzustowski, 2012; Gault, 2018; Kerr, 2020; Organisation for Economic Co-operation and Development [OECD], 2010; Shearmur \& Poirier, 2017; Vinodrai, 2010). It is understood that "knowledge, learning, and innovation are key to economic development" (Todtling \& Trippl, 2005, p. 1203); however, the concept of innovation is multifaceted. Shah, Gao, and Mittal (2015) argue that it has different meanings in different contexts-particularly for cities that are trying to enter the innovation game. Innovation, at its core, is about creating and introducing something new or improved with the intention of creating value (Hisrich \& Kearney, 2014; Sundbo, 1998). Schumpeter (1936) described innovation as a social activity leveraging new combinations or applications of 
knowledge, resources, or equipment, carried out within economic spheres and serving a commercial purpose. While this has historically referred to technological improvement and invention, the Oslo Manual (OECD, 1997, p. 88) extends this to include "non-technological innovation" which suggests that innovation can include processes which do "not relate to the introduction of a technologically new or substantially changed good or service or to the use of a technologically new or substantially changed process." Extending Schumpeter, innovation is not simply about invention but also about new business opportunities (see Drucker, 2014; Hisrich \& Kearney, 2014; Shah et al., 2015). In this context, innovation is not something that happens on its own, but rather a systematic process that can be introduced, learned, and refined. An implication of this is that innovation requires strategic and proactive efforts to occur (Dyer, Gregersen, \& Christensen, 2011)

For cities and their local governments, however, innovation is not about creation but management. The OECD (2018, p. 111) describes innovation management as a process that "covers all activities to initiate, develop, and achieve results from innovation. The relevant capabilities are closely linked to general organisational and managerial capabilities." Processes here include (OECD, 2018, pp. 110-111):

- Identifying, generating, assessing and pursuing ideas for innovation

- Organising innovation activities (i.e., aligning different innovation activities)

- Allocating resources to innovation activities

- Managing innovation activities conducted in collaboration with external partners

- Monitoring the results of innovation activities and learning from experience

Paralleling knowledge-intensive business services, local governments and their practitioners can be seen as enablers of innovation, serving as initiators of innovation activities in a city, facilitators of innovation, and conduits of knowledge transfers (see Aslesen \& Isaksen, 2007; Shearmur \& Doloreux, 2009).

Influencing the role of cities as enablers of innovation is a change in local governance approach. For at least the past thirty years, there has been a spatial restructuring of political power (see Brenner \& Theodore, 2002). For many local and regional governments this meant greater autonomy and responsibility in managing their economic fortunes (see MacCallum, Moulaert, Hillier, \& Vicari, 2009; Shearmur, 2012). Spurred on by similar political-economic issues-including the crumbling of the Keynesian consensus, the shift to postFordism, and the rise of greater global competition for economic resources - cities began adopting forms of urban entrepreneurialism, where local governments and their practitioners adopted a more proactive and market- driven stance towards economic policy (Gillen, 2009; Harvey, 1989; Leslie \& Rantisi, 2006), but also a shift "from a top-down, government-knows-best approach to a more inclusive, multi-sectoral style of local governance" (Wolfe, 2009b, p. 19).

As a result, the local context of a city is necessary for understanding the determinants of firm-level innovation within a city, as this cannot be done in isolation from the environment in which the firms are situated (lammarino, 2011; Malecki, 1987; Shearmur, 2012). Local innovation system approaches-which explain the context in which firms operate-emphasize that each locality has its own institutions and culture, and the variability between places help explain local capacity to foster firm-level innovation (Asheim, Boschma, \& Cooke, 2011; Cooke, 2004; Shearmur, 2011). When considering this local milieu, Wolfe (2009a) argues attention needs to be paid to the interactions of formal and informal institutions that can support this movement towards innovation. Firms and entrepreneurs are embedded within networks of institutions that have key roles in disseminating information, knowledge, and learning which helps facilitate both adaptability and potential for growth (Amin, 2001; Clarke, 1995). In practice, this network of institutions needed for local innovation-and the policy that supports it-becomes one of the partnerships between "businesses, government, post-secondary institutions, innovation centres, entrepreneurs, not-forprofits, and other stakeholders which allow regions to accomplish more by pooling resources and minimizing duplication" (Ontario Chamber of Commerce, 2019, p. 19). As a result, it is important to understand the role that local governments are playing in within this milieu to identify how they enable or facilitate innovation.

Spatiality also matters for innovation. Drawing from broader cluster research (see Porter, 2000), spatial proximity of firms within the same industry allow for sharing of talent, infrastructure, and market; and within the localized economies, the interactions and resulting knowledge spillover is a key determinant of innovation (Potter \& Miranda, 2009; Wolfe, 2009a; Wolfe \& Bramwell, 2016). Alternatively, innovation has been described as the outcome of the formal and informal interactions that occur in places with a diversity of firms, with learning opportunities and transfers of knowledge (both tacit and codified) occurring across different economic sectors (Audretsch, 2002; Florida, 1999; Gertler, 2003; Howells, 2002; Jacobs, 1969). Activity tends to be clustered because it is knowledge-intensive and closely associated with spatially sticky tacit knowledge (Asheim \& Gertler, 2006; Seyfang \& Smith, 2007). Underlying both, however, is that proximity is important-that firms and their workers aggregate within an area (i.e., a city) and that it is this co-locating that helps generate innovation. Again, identifying how local governments view these determinants of innovation helps inform on how cities play a role in enabling innovation. 


\section{Methodology}

To explore the role that innovation plays in local economic development this study employs an inductive grounded theory approach designed to allow logical inferences to be made when evaluating the research questions. First, when evaluating what innovation means to cities and their practitioners in the context of economic development, focus is placed on understanding how practitioners define and conceptualize innovation and its key determinants. For the second research question, on how cities, as institutions, operationalize innovation policy within their local context, the role of local government (through its practitioners) is explored to identify how the policies, actions, and interactions with other institutions are used to shape how local innovation occurs.

Data was collected through semi-structured, indepth interviews with 24 local economic development practitioners from 17 cities in Ontario (Table 1). For cities with multiple practitioners who were interviewed, their responses were weighted so that they did not skew or bias the results. For instance, though six practitioners participated from Richmond Hill (approximately one-quarter of the study participants), in the analysis and reporting, care was taken to make sure their responses were not over-represented, but instead equal to the sixteen other cities represented in the study. The use of interviews presents an opportunity to generate a deeper understanding of innovation and economic development (see Cleave, Arku, Sadler, \& Gilliland, 2016). The practitioners that were recruited came from a range of geographic, political, and economic contexts to create a diversity of perspectives to draw inferences from (Table 1). A vital characteristic in the selection of practitioners was their experience with innovation. The interviews were conducted with economic develop- ment managers that specialized in innovation. If there was no such person, an equivalent role in economic development, or the most senior economic development practitioner was interviewed. Thus, the interviewees included Managing Directors $(n=2)$, Directors $(n=4)$, Sector Managers $(n=4)$, Economic Development Officers $(n=12)$, and Coordinators $(n=1)$. Experience ranged from 1 year to 34 years in economic development, with a median of 5 years of experience. All of the practitioners interviewed had experience with developing or managing a wide range of innovation-focused activities, including the creation of innovation districts (Hamilton, Kitchener, Markham), development of business incubators (Toronto), attraction and creation of high technology facilities such as autonomous vehicle testing sites (Ottawa, Stratford), facilitating improvement within agricultural sectors - both in approaches to farming and materials used-to create greater value-added uses (Prince Edward County, Stratford), and efforts to facilitate networking of entrepreneurs and businesses (London, Vaughan). In addition, purposeful sampling was used to ensure that practitioners from a range of cities were interviewed to ensure diversity of perceptions. As such, cities were grouped into three pools (an approach previously used by Cleave et al., 2019): small-sized ( $<75,000$ population), mid-sized (between 75,000 and 350,000 population), and large-sized cities ( $>350,000$ population), with participants drawn from all three pools (see Table 1).

The majority of the interviews were conducted over the phone, and some interviews were conducted in person. Interviews were semi-structured, ranging from 30 minutes to 60 minutes and averaging approximately 43 minutes in length. A semi-structured interview approach was used to ensure that data was captured in key areas, while still allowing for flexibility for participants

Table 1. Cities included in this study.

\begin{tabular}{lclc}
\hline City & Population (2016 Census) & Size Classification & Participants \\
\hline Barrie & 145,614 & Medium & 1 \\
Brampton & 593,638 & Large & 2 \\
Brant & 36,707 & Small & 1 \\
Hamilton & 536,917 & Large & 1 \\
Kitchener & 233,222 & Medium & 1 \\
Markham & 328,966 & Medium & 1 \\
Mississauga & 721,599 & Large & 1 \\
Ottawa & 934,243 & Large & 1 \\
Pickering & 91,771 & Medium & 2 \\
Prince Edward County & 24,735 & Small & 1 \\
Richmond Hill & 195,022 & Medium & 6 \\
Stratford & 31,465 & Small & 1 \\
Thunder Bay & 107,909 & Medium & 1 \\
Toronto & $2,731,571$ & Large & 1 \\
Vaughan & 306,233 & Medium & 1 \\
Waterloo & 104,986 & Medium & 1 \\
Woodstock & 40,902 & Small & 1 \\
\hline
\end{tabular}


to add their own perspective and experiences. Key questions asked during the interviews included:

- Could you describe what innovation means-both to you and to the city-and how was this conceptualization developed?

- What does innovation mean in the context local economic development?

- Can you please describe how is innovation viewed in the city's economic development strategy? Is it a key strategic priority for the city? If so, how?

- Describe ways the city attempts to foster innovation?

- Does the city have the tools to develop the innovation sector of the economy internally? If so, what strengths or locational advantages to you think your city has? What are any potential weaknesses that might limit the growth of an innovationsector? If not, how do you attract and retain the resources needed to support an innovation-sector?

- Are there other institutions (public and private sector) that you work with to help create an environment for innovation? What is the city's role in this network?

- Innovation-focused policy appears to be popular in Ontario. If that many cities are emphasizing it, how does your city differentiate itself?

- How do you measure innovation?

- In what ways do you think innovation will affect the city's economic development in the future?

All interviews were recorded and were then transcribed, reviewed, and analyzed using NVivo software to identify key themes to create a reliable, standardized framework from which to analyze the discussions and perceptions of the practitioners (Hay, 2005; Seale \& Silverman, 1997). Overarching themes were identified along several general contexts (see Hay, 2005): conditions (the social, political, and physical contexts and the circumstances that necessitated innovation within the city); strategies and tactics (the actions of the city to foster innovation and the perspectives of practitioners related to innovation and its importance); and consequences, which contextualize the outcomes of interaction with a stimulus or phenomenon (as an example, how innovation was measured or policy success determined). The meanings that practitioners attached to innovation were also examined to further understand the relationship between innovation and local economic policy development (Hay, 2005). In the results presented in this article, economic development practitioners are referred to by the acronyms $\mathrm{P} 1$, P2, P3 through P24.

\section{Results}

This section presents the results of the interviews, identifying the key themes that emerged along with supporting quotations. The section is structured to evaluate the two research questions and overall objective of the article. First, it explores what innovation is and what its key determinants are from the perception of the practitioners. It then presents the roles, responsibilities, and challenges the practitioners and local governments face as social institutions, and how it shapes innovation. Throughout this section, the perspectives and actions of practitioners from different-sized cities are identified and contrasted.

\subsection{Perspectives of Practitioners on What Innovation Is}

Emerging from the perspectives of the practitioners (see Table 2), it is evident that innovation is a broad conceptualization with multiple dimensions-existing both as an abstract concept and as tangible set of actions. There was broad agreement amongst the practitioners on what innovation was as an abstract concept (15 of the 17 cities identified this in their responses). Common perceptions of innovation included "a mindset and a culture" (P5). This culture starts from the municipality's internal economic development department, with the goal of extending it across the city. For example, one practitioner described innovation as "fostering a culture of innovation in the team, then broadening out to [their] direct stakeholder community, then the broader city" (P17). To build a culture of innovation, one practitioner emphasized the importance of starting with the right people and processes first, then implementing the "technology and the tools as the last thing" (P11). Other commonalities in perspective included contextualizing innovation as "new ways of doing things" (P6, P7), and "thinking outside the box" (P8). A smaller subset of practitioners (representing 12 of the 17 cities in the study) described innovation as a tangible set of processes by the practitioners, including "improving services" (P9) or "finding efficiencies" (P1). Practitioners also described innovation as value creation, whether "creating new processes" (P17) or "creating an outcome, like a new product or business" (P1). Within this tangible set of processes, innovation was framed as both internal and external to local government. Notably, the majority of practitioners (17 in total, representing 11 of the 17 cities) noted both conceptualizations, suggesting that they hold innovation in a comprehensive way.

\subsection{Divergences in Understandings on Innovation}

An interesting way in which perspectives of the practitioners diverged was about how innovation occurs. The practitioners from the four small cities expressed innovation occurring much more rapidly (closer to invention or creation-focused innovation). Practitioners from midsized (representing 6 of 8 cities) and large municipalities (5 of 5), however, took a Schumpeterian view of how innovation occurs, stressing the concept of incremental changes and imitative innovation rather than radical innovation (taking a more managerial approach). As one practitioner noted: 
Table 2. Summary of practitioner perspectives on innovation.

\begin{tabular}{lll}
\hline Key question & Conceptualization & Examples/Description \\
\hline What is innovation? & An abstract concept. & Culture of the city. \\
& A new way to approach problems (i.e., thinking outside the box). \\
& for cities to use. & Improving city services. \\
& $\begin{array}{l}\text { Designing more efficient government processes. } \\
\text { Identifying, enhancing, and leveraging local assets and key } \\
\text { determinants of innovation. } \\
\end{array}$ & Creating a value-added process or outcome for the city.
\end{tabular}

How is innovation Firm-focused conceptualized?
Emphasis on fast innovation or radical change or improvements. Focus on outcomes-such as new products or ideas (i.e., creation). Private sector-led innovation, passive local government. Found primarily in small cities.

Governance-focused
Local government-led, with focus on innovation management, rather than creation/invention.

Incremental improvement rather than radical innovations.

Focus on organizing local assets to address specific local issues.
Innovation in economic development does not necessarily mean that we need to come up with a brand new approach to something that has never been tried, but we may try something that has not been applied or scaled to the city before. (P17)

One practitioner estimated that they were "95\% focused on imitative and incremental innovation and $5 \%$ focused on new radical innovation" (P17). Imitative innovation may be more impactful in an economic development context because it is less risky, making it easier to work within funding and political constraints. The popularity of imitative innovation may explain the rapid convergence of innovation policies under the guise of using 'best practices' as a rationale to implement new projects and programs.

A second area where there was divergenceparticularly when comparing cities of different sizeswas the context in which innovation was framed (i.e., firm-focused creation or government-focused management). Practitioners-particularly from all four small cities participating in this study-tended to perceive innovation as needing to create an economic outcome, such as a new product or business. The ability to commercialize an idea is critical, with one practitioner noting, "innovation ultimately needs to get to a point where something is being produced, bought, and sold, driving economic impact" (P1). It also needs to "add value from the customer's perspective" or "keep investment here" (P10).

Practitioners from mid-sized ( 5 of 8 cities) and larger municipalities (4 of 5), tended to contextualize innovation from a governance and management perspective, focusing along themes of adding value, problem-solving, and solution creation, with one practitioner explaining: "innovation is not just a matter of creating new things, but it's a matter of creating solutions to address local issues" (P12). From the responses of the practitioners, it is evident that innovation is more than just a new idea, it must "address challenges" (P12) and "add value for the community" (P8). Interestingly, from the perspective of the practitioners, part of adding value means that innovation has to "find solutions to problems" (P9). For other cities, the emphasis is still on disruption and diversification, with one practitioner emphasizing that "innovation means high potential, high impact disruptive companies that can help our key sectors transition" (P11). In summary, a key finding that emerged from the conceptualizations of innovation is that practitioners from mid-sized and large cities see local government as a facilitator of how innovation is conducted.

\subsection{Key Determinants and Drivers of Innovation}

This shaping of innovation also occurs in what local advantages are identified and leveraged (see Table 3). Across all seventeen cities of this study, the practitioners identified technology, talent, entrepreneurship as the key determinants of innovation. This sentiment was reflected by the practitioners who acknowledged that innovation is commonly misperceived to be exclusively focused on technology. One practitioner stressed "the biggest challenge and misconception with innovation is starting with the technology, not the foundation," where the foundation refers to the people and processes of the organization (P11). However, emerging from the responses of the practitioners, it is clear that some cities are starting to shift their strategic priorities as it relates to spurring on local innovation-finding different ways to build up their local capacity. The primary area that was mentioned by all practitioners emphasized improving local characteristics to appear attractive to talent. 
Table 3. Summary of key determinants of innovation.

\begin{tabular}{lll}
\hline Determinant & Description & Examples \\
\hline Traditional & These approaches are more directly focused & Talent attraction/knowledge base . \\
& on innovation and are more similar to & development \\
& traditional economic development and & Business attraction. \\
& innovation perspectives, where emphasis is & Technology. \\
& placed on talent and technology. & Existing innovation infrastructure (i.e., \\
& & universities, firms). \\
& Business Incubators/accelerators.
\end{tabular}

Holistic

Speciality/Proximity/Interaction
Place-making approaches meant to improve quality of life and more generally the local context/characteristics of the city. Generally focused on broader urban or economic issues that have direct relevance for innovation.

The practitioners in this study emphasized the need for talent/entrepreneurs and businesses to be located in close proximity to one another to help facilitate interaction between different firms and people.

\section{Affordable family housing.} Free city-wide Wi-Fi.

Improved place (i.e., better social and cultural amenities, recreational activities and greenspace, improved infrastructure and city scape).

Innovation and research parks.

Business incubators.

Business accelerators.
Practitioners acknowledged that "talent needs to be supported with other amenities" (P13), because "you could have all the jobs and opportunities you want, but those are useless if you don't have anywhere to live" (P12). There is greater emphasis on livability and affordability in economic and community development, as it is becoming clearer to practitioners that employment and livability are becoming more inter-related. The type of people that are filling the jobs facilitated by economic developers want affordability and vibrancy. Focusing on jobs simply is not enough. One practitioner emphasized that "economic development is on a transition to a more holistic approach," which requires them to "start thinking about place-making and affordable housing," because "economic development cannot be pigeon-holed into just employment" (P11). Efforts to improve the local context ranged from "creating affordable and attainable housing for young working families" and creating a new "regulatory structure to regulate short-term accommodation" (P2) to "keeping the city in the cutting edge by investing in city-wide Wi-Fi," with the goal of eventually having every home and business in the city connected (P4). As practitioners recognize their role expanding in scope to involve community functions, they perceive innovation to play an increasingly important role in addressing challenges facing their communities. One practitioner noted that they "can't attract companies if there is nowhere for their employees to live" (P19), and this sentiment was echoed by three other practitioners. The recognition that "the perspective of economic development is changing" because "economic development is not just the business community, it's about attracting people and keeping them here too" (P23) is part of the shift in mindset to become more collaborative and creative with other community partners and municipal functions to solve problems.

Universities and training centres were unanimously identified as key foundational pieces of innovation among mid-sized and large cities. One practitioner noted that "if people aren't equipped with good education and the space to think about entrepreneurship and take risks, you won't get innovation" (P11). There was a common perception that linked research and post-secondary institutions with a strong high-tech sector: "We have a university, college, and an innovation centre" (P10). A further example that linked tangible local assets with broader local economic market characteristics was provided by one practitioner (P16), who highlighted their city's test site for autonomous vehicles which was described as a key part of the city's "huge high-tech sector, [containing] lots of leading-edge research." However, a concern raised by the practitioners was that the same strategies are being employed regularly by different cities, with one practitioner noting "this doesn't fuel innovation, it fuels replication" (P6). This highlights a potential convergence in innovation policies and strategies.

A final key determinant was the presence of existing innovation infrastructure, including innovation parks (Markham, Hamilton), research parks (London), business incubators and accelerators (Waterloo, Toronto), and technology test sites (Ottawa). Interestingly, the majority of practitioners (from 12 of the 17 cities) extended this to argue that the presence of this infrastructure in close spatial proximity was important. One practitioner described their efforts to "curate the innovation district to foster and attract higher value-added uses" improv- 
ing upon previous models by noting that it is "not just a science park campus but will include more supportive amenities and uses for the spaces" (P7). A similar sentiment was expressed by another practitioner (P11) who described their city's plan to create "an employment area to respond to future trends in business" Underlying all of this was the perspective on clustering and proximity similar to that argued by Potter and Miranda (2009) and Wolfe (2009a) with knowledge transfer (11 of the 17 cities) and spillovers (10 of 17) being cited as tangible benefits from the practitioners. An offshoot benefit of this was the interactions that this proximity allowed (as described by Florida, 1999, 2002)-as one practitioner noted (P18): "We wanted to create a space where we could get the smart people together [businesses and talent]. If they can bounce ideas or share resources, that's where some cool ideas can come from."

In summary, the practitioners' responses indicate that the way to drive innovation is changing, mirroring broader changes in local economic development: shifting from more traditional roles of business attraction to a holistic view of developing the community. Many economic developers recognize that their role is more interlinked with fulfilling the needs of the community than with merely attracting businesses and job creation.

\subsection{Economic Development Practitioners and the Institutions Driving Innovation}

Unanimously, the economic development practitioners recognized the importance of innovation in their municipalities, linking it to "job growth, net GDP increase, pulling wealth into the community, and market penetration" (P5). Indeed, the practitioners viewed innovation as something that "drives [their] economy and growth" (P6), with one practitioner indicating that "innovation becomes a higher priority every year" (P5). This critical necessity for innovation was contextualized as "if you're not changing, you're dying" (P6). This perspective was expanded upon by several practitioners, arguing: "The governments who are the best at adopting new things will be more likely to succeed, whereas those who stick with the same processes are unlikely to adapt to a quickly changing world" (P17) and "we know we have to be innovative, and we have to come up with new ideas" (P12).

There was a notable divide-based on city sizewhen considering the role that practitioners and local government played in managing innovation. Aligning with their conceptualization that innovation was firm-based and emphasized creation, all four small cities agreed that "innovation is more private sector driven" (P10), where there was a limited role for local government. Even in this case, however, the economic development practitioners did still acknowledge that the city had some power in shaping how innovation occurred, as through zoning and by-laws. In particular, this controlled where entrepreneurs and firms could locate within a city, as justified by one practitioner (P22):
The city has made sure that land is available to support this type of innovation related activity and that's where we want the businesses to go. This is us putting a stake in a ground about businesses not coming in with land conversion requests.

For mid-sized (7 of 8) and large cities (5 of 5), more proactive management of innovation was described as occurring-generally being prioritized because of its importance within municipal governance and politics, as "[city] councillors will see the term innovation and agree with it, it will get attention" (P11). Overall, economic development practitioners noted the links between innovation and economic growth, which as a result made it a priority on the economic and political agendas. As a result, practitioners, the local economic development offices, and city governments exhibited tendencies of urban entrepreneurialism where they took an active role in shaping the city's local context by influencing how key determinants of innovation were cultivated and leveraged (summarized in Table 4), as well as taking more direct strategies. In particular, investment was identified as a key approach by the majority of practitioners from mid-sized cities. This approach included "directly funding a regional research facility" (P10), "accelerator funding," and "pooling dollars with other communities to conduct foreign direct investment programs such as international trade shows, trade missions, and investment seminars" (P4). Other programs included "investing in a project to digitize the festival's shows to promote to the world, with the intention of helping the tourism industry" (P4). In this regard, while the cities are not the node of innovation, they are an important institution in creating the context for innovation and directly supporting it (contrasting the more passive approach described to be occurring in the small cities).

An example of investment guiding local innovation was expressed by practitioners when discussing Ottawa's focus on specializing in autonomous vehicle test sites. Driving innovation in this direction included "investing in infrastructure in stoplights so autonomous vehicles can communicate to the infrastructure in the city" (P4). The City of Ottawa's Innovation Pilot Program was identified as an initiative that allows companies to pilot innovative technologies that align with the city's line of business. Ottawa was not unique in their approach, as other cities were described as having similar programs, where local government works with companies to test an emerging technology that has not found a commercially viable market yet. This program is a novel approach to "test new equipment and technology that can help the business grow" (P9).

Across all cities, a common theme was the role of practitioners and the local government acting as a facilitator or conduit for networking with other institutions (i.e., firms, universities, venture capitalists, and business incubators). These networking activities were identified as shorter-term innovation-focused events that were 
Table 4. Summary of institutional efforts and challenges.

\begin{tabular}{|c|c|c|}
\hline Institutional issues & Context & Examples/Description \\
\hline \multirow[t]{6}{*}{ Approaches } & \multirow{3}{*}{$\begin{array}{l}\text { Direct approaches-where the government } \\
\text { takes a direct and leading role guiding } \\
\text { innovation. Responses found this to be } \\
\text { occurring in larger cities. }\end{array}$} & $\begin{array}{l}\text { Zoning and by-laws controlling land use and where } \\
\text { firms can locate. }\end{array}$ \\
\hline & & $\begin{array}{l}\text { Direct financial interventions (i.e., grants, } \\
\text { investments coming from the city-particularly } \\
\text { mid-sized cities). }\end{array}$ \\
\hline & & Marketing (i.e., trade shows or missions). \\
\hline & \multirow{3}{*}{$\begin{array}{l}\text { Facilitating approaches-where the } \\
\text { government plays a role in facilitating } \\
\text { innovation in a less direct way. Emphasis is on } \\
\text { business-led innovation (particularly in small } \\
\text { cities) and networking of firms and people. }\end{array}$} & Organizing pitch meetings/challenges. \\
\hline & & Operating mentorship programs. \\
\hline & & $\begin{array}{l}\text { Hosting networking events with other local } \\
\text { institutions (i.e., businesses, incubators, } \\
\text { universities) to facilitate interactions and promote } \\
\text { collaboration and partnerships. }\end{array}$ \\
\hline \multirow[t]{2}{*}{ Challenges } & Policy convergence. & $\begin{array}{l}\text { A key issue noted by the practitioners is that cities } \\
\text { are attempting similar core approaches to } \\
\text { innovation-such as business incubators-which } \\
\text { the practitioners noted creates risk for } \\
\text { communities with limited local strengths. }\end{array}$ \\
\hline & $\begin{array}{l}\text { Determining effective planning and } \\
\text { quantifying innovation policy. }\end{array}$ & $\begin{array}{l}\text { Policy and action are ways in which the city } \\
\text { government shapes the local context that create } \\
\text { the conditions for innovation. However, measuring } \\
\text { outcomes is difficult, which limits the ability of } \\
\text { cities to craft meaningful or useful policy. }\end{array}$ \\
\hline
\end{tabular}

perceived to be successful at gathering collaborators. Innovation projects such as "grant programs, pitch challenges, or mentor programs" are more "event-focused," making it easier for members of the community to commit to collaborating with each other and with the city (P22). More tangibly, this was described as:

One of the most important roles for us is to be a matchmaker. We recruited corporate people (Ikea, Loblaws, utility companies) to come and act as mentors and judges and ecosystem players with startups. The goal is to connect startups with multinational corporations and their funding. If we can't connect startups with funding from the City, maybe we can connect them the corporations. (P20)

The key implications are that cities are not the only institution involved in driving innovation, but they feel they play an important management role, coordinating and managing all the different parts of the ecosystem to ensure optimal local conditions for innovation.

Based on the perspectives of the practitioners, two key institutional challenges related to policy were identified. The first considers policy convergence and how to measure outcomes or determine policy effectiveness (see Table 4). While there was divergence in the way innovation is framed within local economic develop- ment, there is convergence in the core strategies that cities have typically employed to foster it. There was wide agreement across the practitioners interviewed that demonstrates a convergence in innovation strategies employed. One area of convergence was the near unanimous identification of business incubators, accelerators and innovation centres as the foci of local development efforts-which stress the importance of publicprivate partnership in innovation. Nearly every practitioner (from 13 of the 17 cities) noted local centres that were meant to be "equivalent to MaRS in Toronto and Communitech in Kitchener" (P14). Inevitably, cities are competing for the same provincial pools of money, resources, and talent, so reliance on the same strategies may give places with natural advantages better ability to tap these pools. Cities that lack these natural advantages may find it difficult to catch up.

The second issue related to policy is a lack of measurement of outcomes. The majority of the practitioners noted that their local government did not measure innovation outcomes in their local economies, with one practitioner noting "innovation is not something we can measure" (P8). Part of the difficulty stems from ideas that metrics around innovation require more time and resources, through more "qualitative evidence rather than quantitative evidence" (P6), and that "there's also an intangible effect that is hard to measure" (P18). Closely 
related is the lack of data on innovation outcomes. Practitioners noted that they "rely on [their] community partners, using different sources and methods" (P12), such as "workforce planning boards" (P6), "local accelerators" (P12), and "open data portals from the federal government" (P1). The challenge is typically relying on data from private corporations, with one practitioner highlighting that "sometimes companies don't want to share what they're doing...so there are challenges in collecting the information we need to track progress" (P1). As a result, there is an institutional challenge as incomplete data makes it difficult for relevant or useful policy, regulation, and action to be implemented.

\subsection{Challenges Facing Cities and the Role of Innovation}

Several of the challenges identified were related to the ability of cities to effectively foster innovation. This spanned both how innovation was conceptualized and operationalized (see Tables 2 and 4). While there was agreement among practitioners on innovation as a highlevel concept, divergences emerged when deeper definitions and understandings were explored. Practitioners unanimously agreed that there is considerable disagreement on what innovation is, as it is dynamic and ambiguous, making it difficult to identify and target. This was articulated by one practitioner as "everyone has a different definition of what innovation is. What is innovative in one community may not be innovative in another" (P12). The divergences in what innovation is ranged from emphasis on the commercialization of new products, to creating solutions and value through products, processes, or services.

When discussing how key determinants of innovation are operationalized and leveraged, several challenges emerged. The most commonly described challenge related to talent attraction and matching ( 8 of the 17 cities). Many cities are seeing a "large unmet demand for skilled labour and trades" (P12), while other cities are struggling with "attracting people to jobs in the region and the city and trying to keep them" (P12). One practitioner noted how this challenge manifests in different sectors. For example, "in the technology sector, companies are struggling to find senior staff and keep new graduates here for the long haul," whereas "in manufacturing, there is a shortage of skilled trades at both senior and entry level positions" (P13). These challenges place talent attraction as a top priority for many economic developers, making it more important for cities to establish close relationships with universities and colleges.

Another commonly described challenge among all cities is the uneven nature of economic development, as local context matters. Practitioners in smaller cities (4 of 4) felt that innovation was tough because "universities play a key role, and we [small cities] just don't have that building block" (P5). Another practitioner in a small municipality expressed frustration over a lack of messaging around innovation occurring in smaller cities, stressing that "there is more innovation happening beyond the Waterloo-Toronto corridor, but there is no messaging about innovation beyond the GTA on the federal level" (P11). Even among larger cities, there is a challenge in ensuring more equitable access to job and capital opportunities, as many of these opportunities are concentrated in downtown clusters in the city. A practitioner from a large city (P10) noted that "there is lots of concentration of economic activity in the downtown core" and one of their main challenges is to "ensure that the outer parts of the city have access to the same type of opportunity."

Other social institutions also were identified by the practitioners as hampering the ability of cities to drive innovation. Public scrutiny, the political climate, and government regulation were also challenges that were perceived to limit innovation. These challenges relate to the nature of the role of economic developers. One practitioner noted that "innovation requires risk-taking, but when you spend resources that don't immediately benefit, it can be perceived negatively" (P7). Additionally, the roles that economic developers play are "highly regulatory functions...so there is not a lot of room for innovation" (P7). Lastly, the political climate is also known to play a role in constraining resources. A practitioner described how before the Conservative government took power, "the provincial government was a big financial supporter of the innovation ecosystem. If we don't have the dollars to support our programming, it creates challenges" (P6). Overall, there are many challenges facing economic developers as it relates to developing innovation in their communities.

\section{Discussion and Conclusion}

The overarching goal of this study was to explore the way that innovation was conceptualized by local economic development practitioners and how it was operationalized by cities in Ontario. Framing these questions was that local economic development practitioners and the city governments they represent are key social institutions (Martin, 2003; Vidal \& Peck, 2012) that had the potential to shape both the local context of the city and the way that innovation was approached (Wolfe \& Bramwell, 2016). Interestingly, the responses of the practitioners were in strong agreement with each other and aligned with the academic literature: Innovation is a key driver of economic development in cities around the world (see Florida, 2002; Hall, 1999; Shearmur, 2009; Vinodrai, 2010). Beyond this there was considerable disagreement in how to conceive and operationalize innovation.

It was clear from the responses of the practitioners that views of innovation in economic development varied across different cities, reflecting a lack of a consistency in how it was conceived. There was division on whether innovation was tangible or intangible, creationfocused or managerial, private sector or public, and rapid or incremental. Interestingly, many of these deviations 
occurred along the sizes of cities. This suggests that the local context, and perhaps the resources and capacity of local government play an active role in how innovation is understood and focused. Smaller cities with less capacity were far more passive and deferential to businesses; however, cities with larger populations (and by extension greater resources) described themselves as far more proactive, taking a leadership role in guiding innovation through investment, policy, and action.

Notably, while there were differences in how innovation was conceptualized, the projects being implemented across the province demonstrate a convergence in innovation policy and action, with many cities employing similar strategies. For example, innovation centres are described as the equivalent of other innovation centres in larger cities, with frequent comparisons to centres such as MaRS in the City of Toronto. Innovation centres are being established primarily to encourage the development of small businesses involved in advanced technology. It appears that local policies and projects such as innovation centres are being informed by the work of scholars that see future economic prosperity of nations and local economies as depending on creative industries, high-technology industries, and attracting highly educated workers (e.g., Florida, 2002; Gertler, Gates, Florida, \& Vinodrai, 2002). This elucidates an incongruency - though cities and their practitioners have differing views on innovation the outcomes are ultimately similar. Three potential explanations are: 1 ) that the way innovation is perceived does not actually affect outcomes as all cities are operating in the same competitive global economic environment and facing the same challenges; 2 ) that there are other-external-social institutions (i.e., regional governments, consultants, and potentially other cities) which could lead to policy migration where local communities copy the practices of each other (Buttazzoni, Arku, \& Cleave, 2019); and, most likely (based on the practitioners' responses), 3) that while there are core similarities and convergence of some policies and efforts, there are differences around the margins that are shaped by the local economic development office and city government. Examples of this include the focus on autonomous vehicles in Ottawa, or the efforts of high-tech agriculture in Prince Edward County, or the different placemaking strategies that were noted to attract entrepreneurs across all the study cities. Since talent and technology are seen as core elements to innovationboth in scholarship and practice-they may be what cities are most focused on. However, from the responses of the practitioners, there are many ways in which a local environment for innovation is created. Based on the scope of the institutional influence that local governments have and the entrepreneurial and proactive approaches to planning and policymaking being taken, it is likely that they are trying to adopt meaningful localespecific policy to help address local challenges. However, because of the success of certain approaches (i.e., incubators), they are seen as best-practices and should be adopted. For cities, a potential solution to overcome this disconnect may be to focus on their local advantages (i.e., context-specific approaches), rather than high-usage and standard strategies, to better facilitate innovation. For example, while every city should act as a conduit between groups and help enable networking, they need to do so in a way that reflects the local context and configuration of innovation-related institutions.

Related, the commonality of policies raises questions about whether communities are leveraging their local assets and strengths as key determinants of innovation. This question is legitimate given scholarly evidence of a high rate of failure among small businesses that are located in innovation centres (Leigh \& Blakely, 2017). The high failure rate has been attributed to the fact that the high-tech small businesses in innovation centres are removed from major businesses or users that they serve. This suggests the importance of local assets and environment in any policies and projects aimed at enhancing innovation.

Increasingly, practitioners see their role as becoming more holistic, extending beyond traditional functions in economic development such as business attraction and retention. Practitioners described how they are taking on more community-level functions such as ensuring the livability of the community through increased investment in arts and culture and affordable housing. The main challenges facing economic development practitioners are talent attraction and retention, especially in the smaller communities and to some extent in the midsized cities. This finding is consistent with recent evidence in Ontario about the difficulty mid-sized communities are facing in attracting and retaining highly skilled individuals (Clemens \& Buzzelli, 2015). Practitioners also stressed a challenge in a mismatch in skills and job openings, both in filling jobs that require skilled labour, as well as retaining high-tech talent in the community. This also reflects a greater challenge in the uneven nature of economic development, which tends to cluster in larger cities.

The findings in this study provide interesting and significant perspectives on cities and an overview of recent approaches to innovation in economic development. With cities around the world continuing to prioritize innovation as a key to economic growth, this research contributes to a small but growing field about innovation in the public sector, which has not been studied as extensively as innovation in the private sector. Further research should explore the changing nature of the economic development function into a more holistic community development role, and the processes by which economic developers foster a culture of innovation in their communities.

\section{Acknowledgments}

The authors would like to express their gratitude to all the economic development practitioners who participated in this study. Their insights were essential. The au- 
thors would also like to thank the three anonymous reviewers for their valuable feedback.

\section{Conflict of Interests}

The authors declare no conflict of interests.

\section{References}

Amin, A. (2001). Moving on: Institutionalism in economic geography. Environment and Planning $A$, 33(7), 1237-1241.

Arku, G. (2015). Economic development practices of cities in Ontario, Canada. Community Development, 46(5), 604-615.

Asheim, B., \& Gertler, M. (2006). The geography of innovation: Regional innovation systems. In J. Fagerberg (Ed.), The Oxford handbook of innovation (pp. 1-29). Oxford: Oxford Handbooks Online.

Asheim, B., Boschma, R., \& Cooke, P. (2011). Constructing regional advantage. Platform policies based on related variety and differentiated knowledge bases. Regional Studies, 45(6), 1-12.

Aslesen, H., \& Isaksen, A. (2007). New perspectives on knowledge-intensive services and innovation. Geografiska Annaler: Series B, Human Geography, 89(1), 45-58.

Audretsch, D. (2002). Understanding entrepreneurship across countries and over time. In D. Audretsch, R. Thurik, I. Verheul, \& S. Wennekers (Eds.), Entrepreneurship: Determinants and policy in a European-US comparison (pp. 1-10). New York, NY: Springer.

Bradford, N., \& Wolfe, D. (2013). Governing regional economic development: Innovation challenges and policy learning in Canada. Cambridge Journal of Regions, Economy and Society, 6(2), 331-347.

Bramwell, A., Nelles, J., \& Wolfe, D. (2008). Knowledge, innovation and institution: Global and local dimensions of the ICT cluster in Waterloo, Canada. Regional Studies, 42(1), 101-116.

Bramwell, A., \& Wolfe, D. (2008). Universities and regional economic development: The entrepreneurial University of Waterloo. Research Policy, 37(8), 1175-1187.

Brenner, N., \& Theodore, N. (2002). Cities and the geographies of actually existing neoliberalism. In N. Brenner, \& N. Theodore (Eds.), Spaces of neoliberalism: Urban restructuring in North America and Western Europe (pp. 2-32). Oxford: Blackwell.

Brzustowski, T. (2012). Why we need more innovation in Canada: And what we must do to get it. Ottawa: Invenire.

Buttazzoni, A., Arku, G., \& Cleave, E. (2019). Practitioners' perspectives on in-house versus arm's-length model of economic development delivery in Ontario, Canada. Local Government Studies, 45(6), 913-936.

Clarke, S. (1995). Institutional logics and local economic development: A comparative analysis of eight American cities. International Journal of Urban and Regional Research, 19(4), 513-533.

Cleave, E., Arku, G., Sadler, R., \& Gilliland, J. (2016). The role of place branding in local and regional economic development: Bridging the gap between policy and practicality. Regional Studies, Regional Science, 3(1), 207-228.

Cleave, E., Vecchio, M., Spilsbury, D., \& Arku, G. (2019). Manufacturing change and policy response in the contemporary economic landscape: How cities in Ontario, Canada understand and plan for manufacturing. Regional Studies, Regional Science, 6(1), 469-495.

Clemens, K., \& Buzzelli, M. (2015). The role of higher education in highly skilled labour attraction and retention in medium-sized city-regions of Canada. Annali di Ricerche e Studi di Geografia, 71(1), 3-12.

Cooke, P. (2004). The regional innovation system in Wales: Evolution or eclipse? In P. Cooke, M. Heidenreich, \& H. Braczyk (Eds.), Regional innovation systems: The role of governance in a globalized world (pp. 214-233). London: Routledge.

Drucker, P. (2014). Innovation and entrepreneurship. New York, NY: Routledge.

Dyer, J., Gregersen, H., \& Christensen, C. (2011). The innovator's DNA. Boston, MA: Harvard Business School Press.

Florida, R. (1999). The role of the university: Leveraging talent, not technology. Issues in Science and Technology, 15(4), 67-73.

Florida, R. (2002). The economic geography of talent. Annals of the Association of American Geographers, 92(4), 743-755.

Gault, F. (2018). Defining and measuring innovation in all sectors of the economy. Research Policy, 47(3), 617-622.

Gertler, M. (2003). Tacit knowledge and the economic geography of context, or the undefinable tacitness of being (there). Journal of Economic Geography, 3(1), 75-99.

Gertler, M., Gates, G., Florida, R., \& Vinodrai, T. (2002). Competing on creativity: Placing Ontario's cities in North American context. Toronto: Urban Institute.

Gillen, J. (2009). The co-production of narrative in an entrepreneurial city in turmoil: An analysis of Cincinnati, Ohio. Geografiska Annaler Series B: Human Geography, 91(2), 107-122.

Hall, P. (1999). Cities in civilization. London: Phoenix Books.

Harvey, D. (1989). From managerialism to entrepreneurialism: The transformation in urban governance in late capitalism. Geografiska Annaler. Series B, Human Geography, 71(1), 3-17.

Hay, I. (2005). Qualitative research methods in geography. Oxford: Oxford University Press.

Hisrich, R., \& Kearney, C. (2014). Managing innovation and entrepreneurship. Thousand Oaks, CA: Sage. 
Holmes, J., Rutherford, T., \& Carey, J. (2017). Challenges confronting the Canadian automotive parts industry: What role for public policy? Canadian Public Policy, 43(S1), S75-S89.

Howells, J. (2002). Tacit knowledge, innovation and economic geography. Urban Studies, 39(5/6), 871-884.

lammarino, S. (2011). Regional innovation and diversity. In P. Cooke, B. Asheim, R. Boschma, R. Martin, D. Schwartz, \& F. Todtling (Eds.), Handbook of regional innovation and growth (pp. 143-154). Cheltenham: Edward Elgar.

Jacobs, J. (1969). The economy of cities. New York, NY: Random House.

Kerr, W. (2020). The gift of global talent: Innovation policy and the economy. Innovation Policy and the Economy, 20(1), 1-37.

Leigh, N., \& Blakely, E. (2017). Planning local economic development: Theory and practice (6th ed.). Thousand Oaks, CA: Sage.

Leslie, D., \& Rantisi, N. (2006). Governing the design economy in Montréal, Canada. Urban Affairs Review, 41(3), 309-337.

Lundvall, B., Johnson, B., Andersen, E., \& Dalum, B. (2002). National systems of production, innovation and competence building. Research Policy, 31(2), 213-231.

MacCallum, D., Moulaert, F., Hillier, J., \& Vicari, S. (2009). Social innovation and territorial dynamics. Farnham: Ashgate.

Malecki, E. (1987). The R\&D location decision of the firms in "creative" regions-A survey. Technovision, 6(2), 205-222.

Martin, R. (2003). Institutional approaches in economic geography. In E. Sheppard \& T. Barnes (Eds.), A companion to economic geography (pp. 77-95). Oxford: Blackwell.

Ontario Chamber of Commerce. (2019). The great mosaic: Reviving Ontario's regional economies. Toronto: Ontario Chamber of Commerce.

Organisation for Economic Co-operation and Development. (1997). Oslo manual: Guidelines for collecting, reporting and using data on innovation (2nd ed.). Paris: Organisation for Economic Co-operation and Development.

Organisation for Economic Co-operation and Development. (2010). Innovation to strengthen growth and address global and social challenges. Paris: Organisation for Economic Co-operation and Development. Retrieved from https://www.oecd.org/sti/45326349. pdf

Organisation for Economic Co-operation and Development. (2018). Oslo manual: Guidelines for collecting, reporting and using data on innovation (4th ed.). Paris: Organisation for Economic Co-operation and Development.

Porter, M. (2000). Location, competition, and economic development: Local clusters in a global economy. Economic Development Quarterly, 14(1), 15-34.
Potter, J., \& Miranda, G. (2009). Clusters, innovation and entrepreneurship. Paris: Organisation for Economic Co-operation and Development.

Sadler, R., Cleave, E., Arku, G., \& Gilliland, J. (2016). A comparative analysis of place branding in Michigan and Ontario. Urban Research \& Practice, 9(1), 16-36.

Schumpeter, J. (1936). The theory of economic development. Cambridge, MA: Harvard University Press.

Seale, C., \& Silverman, D. (1997). Ensuring rigour in qualitative research. European Journal of Public Health, $7(4), 379-384$.

Seyfang, G., \& Smith, A. (2007). Grassroots innovations for sustainable development: Towards a new research and policy agenda. Environmental Politics, 16(4), 584-603.

Shah, R., Gao, Z., \& Mittal, H. (2015). Innovation, entrepreneurship, and the economy in the US, China, and India: Historical perspectives and future trends. Cambridge, MA: Academic Press.

Shearmur, R. (2007). The new knowledge aristocracy: The creative class, mobility and urban growth. Work Organisation, Labour and Globalization, 1(1), 31-47.

Shearmur, R. (2009). Space, place and innovation: A distance-based approach. The Canadian Geographer, 54(1), 46-67.

Shearmur, R. (2011). Innovation, regions and proximity: From neo-regionalism to spatial analysis. Regional Studies, 45(9), 1225-1243.

Shearmur, R. (2012). Are cities the font of innovation? A critical review of the literature on cities and innovation. Cities, 29, S9-S18.

Shearmur, R., \& Doloreux, D. (2009). Place, space and distance: Towards a geography of knowledge-intensive business services innovation. Industry and Innovation, 16(1), 79-102.

Shearmur, R., \& Poirier, V. (2017). Conceptualizing Nonmarket Municipal Entrepreneurship: Everyday Municipal Innovation and the Roles of Metropolitan Context, Internal Resources, and Learning. Urban Affairs Review, 53(4), 718-751.

Sundbo, J. (1998). The organization of innovation in services. Frederiksberg: Roskilde University Press.

Taabazuing, M., Arku, G., \& Mkandawire, P. (2015). Economic development in a changing global environment: What do practitioners think? Urban Research and Practice, 8(2), 145-164.

Todtling, F., \& Trippl, M. (2005). One size fits all? Towards a differentiated regional innovation policy approach. Research Policy, 34(8), 1203-1219.

Vidal, M., \& Peck, J. (2012). Sociological institutionalism and the socially constructed economy. In E. Sheppard, T. Barnes, \& J. Peck (Eds.), The Wiley-Blackwell companion to economic geography (pp. 594-611). Oxford: Wiley.

Vinodrai, T. (2010). The dynamics of economic change in Canadian cities: Innovation, culture, and the emergence of a knowledge-based economy. In P. Filion, T. Bunting, \& R. Walker (Eds.), Canadian cities in transi- 
tion (4th ed., pp. 87-109). Oxford: Oxford University Press.

Wolfe, D. (2009a). The strategic management of core cities: Path dependence and economic adjustment in resilient region. Cambridge Journal of Regions, Economy and Society, 3(1), 139-152.

Wolfe, D. (2009b). 21st century cities in Canada: The geography of innovation. Ottawa: The Conference Board of Canada.

Wolfe, D., \& Bramwell, A. (2016). Innovation, creativity and governance: Social dynamics of economic perfor- mance in city-regions. Innovation: Management, Policy \& Practice, 18(4), 449-461.

Wolfe, D., \& Gertler, M. (2001). Globalization and economic restructuring in Ontario: From industrial heartland to learning region? European Planning Studies, 9(5), 575-592.

Wolfson, J., \& Frisken, F. (2000). Local response to the global challenge: Comparing local economic development policies in a regional context. Journal of Urban Affairs, 22(4), 361-384.

\section{About the Authors}

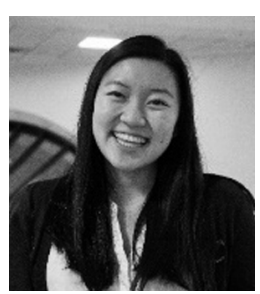

Selina Phan received her B.A. (Hons) in Geography (Urban Development) from Western University (London, Canada) and her Honours Business Administration (HBA) from the Richard Ivey School of Business in 2020. Her research interests include local economic development, innovation ecosystems, and urban resilience.

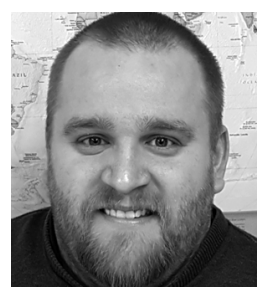

Evan Cleave is an Assistant Professor in the Department of Geography and Environmental Studies at Ryerson University (Toronto, Canada). His research focuses on urban and local economic development policy and planning, including how and why policy is formulated by local governments, as well as its effectiveness in addressing local challenges. His research also focuses on issues related to place branding and marketing.

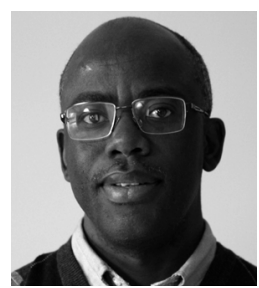

Godwin Arku is an Associate Professor in the Department of Geography at the University of Western Ontario (London, Canada). His research examines local impacts and community responses to global economic, social, and environmental changes. Within this field, he looks at issues such as local impacts and policy responses to plant closures, municipal economic development policies, transnationalism, and immigrant housing, impacts of economic liberalization on housing markets, and economic reforms and built environment changes. 